\title{
Longitudinal assessment of vibrations during manual and power wheelchair driving over select sidewalk surfaces
}

\author{
Erik Wolf, PhD; ${ }^{1-2}$ Rory A. Cooper, PhD; ${ }^{1-3^{*}}$ Jonathan Pearlman, PhD; ${ }^{2-3}$ Shirley G. Fitzgerald, PhD; ${ }^{2-3}$ \\ Annmarie Kelleher, MS, OTR/L, ATP ${ }^{2-3}$ \\ ${ }^{1}$ Department of Bioengineering, School of Engineering, University of Pittsburgh, Pittsburgh, PA; ${ }^{2}$ Human Engineering \\ Research Laboratories, Department of Veterans Affairs Pittsburgh Healthcare System, Pittsburgh, PA; ${ }^{3}$ Department \\ of Rehabilitation Sciences and Technology, School of Health and Rehabilitation Sciences, University of Pittsburgh, \\ Pittsburgh, PA
}

\begin{abstract}
Wheelchair users rely on their wheelchairs for mobility for extended periods of time every day. According to the International Standards Organization 2631-1 standard on human vibration, individuals in a seated position when exposed to whole-body vibrations (WBV) are at risk of injury. This study evaluated vibration exposure during manual and power wheelchair driving over nine sidewalk surfaces and differences in vibration exposure over 3 years. Ten nondisabled subjects were asked to drive a manual wheelchair at $1 \mathrm{~m} / \mathrm{s}$ and a power wheelchair at $1 \mathrm{~m} / \mathrm{s}$ and $2 \mathrm{~m} / \mathrm{s}$ over nine sidewalk surfaces while WBV were measured at the seat and footrest of the wheelchair. At $1 \mathrm{~m} / \mathrm{s}$, significant differences existed between surfaces and years at both the seat and the footrest for the manual and power wheelchair users. At $2 \mathrm{~m} / \mathrm{s}$, significant differences existed between surfaces and years at the seat and the footrest for power wheelchair users. Our results show that both manual and power wheelchair users may be at risk for secondary injuries from WBV when traveling over certain surfaces.
\end{abstract}

Key words: accessible surface, concrete, injury, manual wheelchair, power wheelchair, rehabilitation, sidewalks, vibration, wheelchairs, whole-body vibrations.

\section{INTRODUCTION}

Users of both manual and power wheelchairs use their wheelchairs for mobility for extended periods of time every day [1]. This extensive use, combined with bumps, uneven driving surfaces, and other obstacles, can expose wheelchair users to harmful whole-body vibrations (WBV), which can lead to secondary injuries, such as low-back and neck pain, muscle ache and fatigue, and other harmful effects [2]. Few studies have reported the vibration levels experienced by manual wheelchair users, and even fewer have reported the levels experienced by power wheelchair users. This study examined different sidewalk surfaces and the resulting WBV that were transmitted during manual and power wheelchair driving. Differences in vibration exposure over 3 years were also examined.

A literature review revealed that little research has been conducted on exposure to WBV over various surfaces during wheeled mobility, such as bicycle riding, inline skating, baby stroller use, and motor-scooter driving. Thompson and Bélanger looked at vibration during in-line

Abbreviations: ICP $=$ interlocking concrete pavement, ICPI = Interlocking Concrete Pavement Institute, ISO = International Standards Organization, RMS = root-mean-square, VA = Department of Veterans Affairs, WBV = whole-body vibrations.

* Address all correspondence to Rory A. Cooper, PhD; Human Engineering Research Laboratories, VA Pittsburgh Healthcare System, 7180 Highland Dr, 151R-1H, Pittsburgh, PA 15206; 412-365-4850; fax: 412-365-4858. Email: rcooper@pitt.edu

DOI: 10.1682/JRRD.2006.05.0049 
skating; however, they only studied a standard paved road and did not examine any other surfaces [3]. A study done in Italy by Frendo et al. examined vibrations during motor-scooter driving over different street surfaces, including heavy paved brick, light paved brick, and cobblestone [4]. Results revealed differences between the surfaces, with the light paved brick resulting in the lowest transmitted vibrations and the cobblestone surface the highest.

Multiple studies have shown the negative effects associated with exposure to WBV on humans in seated positions [5-8]. Occupations where WBV are a concern include heavy machinery operation, bus and truck driving, and helicopter piloting. These industries, as well as the automotive industry, have taken measures to reduce the amount of WBV transmitted to their employees [9-11].

The problem of WBV has been recognized by the wheelchair community, and efforts have been made to quantify the amount of vibration transmitted to wheelchair users during propulsion. VanSickle et al. showed that manual wheelchair users traveling over a simulated road course experienced levels of vibrations that exceeded the "fatigue-decreased performance boundary" and could cause fatigue and injury [12]. Wolf et al. evaluated vibration exposure while wheelchair users traveled over different sidewalk surfaces [13]. They found differences between interlocking concrete pavement (ICP) surfaces and a standard poured concrete surface. In some cases, the ICP surfaces caused lower WBV than the standard poured concrete surface. Maeda et al. issued questionnaires to 33 wheelchair users and tested 10 wheelchair users on a vibration platform [14]. Results from the questionnaire revealed that wheelchair users did feel WBV at the neck, back, and buttocks during propulsion and that users sensed differences while traveling over different surfaces and obstacles.

Wheelchair companies have attempted to address this problem by adding suspension to manual and power wheelchairs; however, studies have demonstrated that these additions do not necessarily reduce the amount of oscillatory and shock WBV. Additionally, in the case of manual wheelchairs, titanium rigid-frame wheelchairs without suspension performed better than some wheelchairs with suspension [15-17].

The International Standards Organization (ISO) standard 2631-1, "Mechanical vibration and shockEvaluation of human exposure to whole-body vibrationPart 1: General requirements," was established to define the methods of collection, the effects, and the health concerns associated with WBV [18]. The standard defines a health guidance caution zone (Figure 1), which characterizes the amount of WBV considered unsafe. When exposure to WBV is evaluated over long periods of time, lower cumulative levels are considered harmful $\left(<1 \mathrm{~m} / \mathrm{s}^{2}\right.$ of weighted root-mean-square (RMS) acceleration at 8 hours of exposure). The harmful effects of WBV can be negated by an 8-hour rest period; however, this is extremely rare during an ordinary day of a manual or power wheelchair user, and through days, months, and years, cumulative exposure to WBV could result in secondary injuries.

This research evaluated the WBV experienced by manual and power wheelchair users as they traveled over select sidewalk surfaces as well as differences in exposure over time. We hypothesized that different surfaces would induce significantly different WBV, which suggests that some surfaces are less likely to cause secondary injuries to wheelchair users. Furthermore, we hypothesized that over time, the surfaces would become smoother from weather-related wear and thus result in significantly lower WBV.

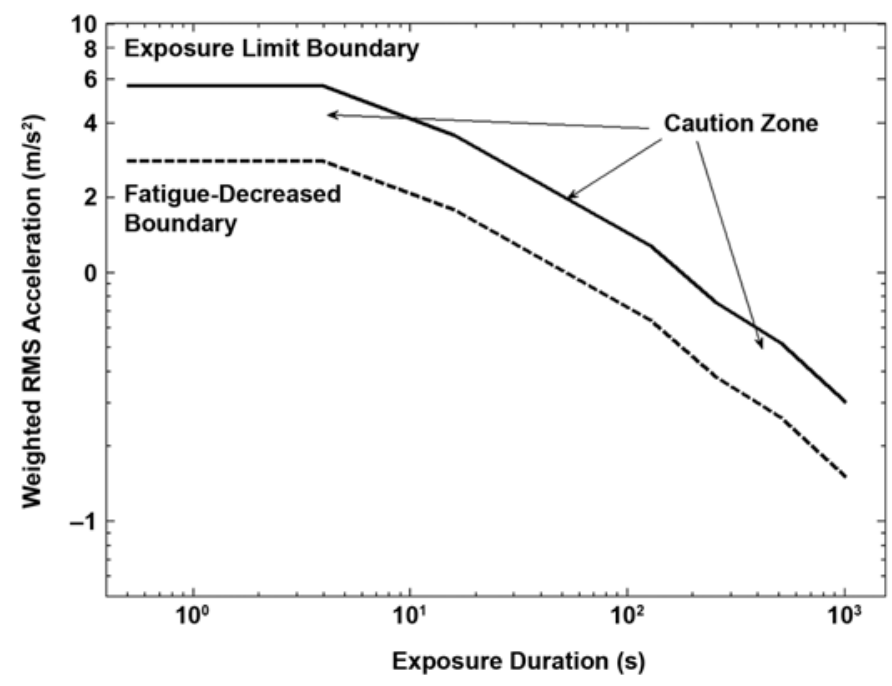

Figure 1.

Limit boundaries of human exposure to whole-body vibrations defined by International Standards Organization 2631-1 standard. Source: International Standards Organization (ISO). ISO 2631-1: Mechanical vibration and shock-Evaluation of human exposure to whole-body vibration-Part 1: General requirements. Geneva (Switzerland): International Standards Organization; 1997. RMS = root-mean-square. 


\section{METHODS}

Six different sidewalk surfaces were tested in three consecutive years (May 2002, July 2003, and June 2004). All the sidewalk surfaces were approximately $1.2 \mathrm{~m}$ wide and $7.6 \mathrm{~m}$ long. Surface 1 was a poured concrete sidewalk with a brush finish, which acted as the control surface. Surfaces 2, 3, and 4 were made from ICP installed to industry specifications [19] and were installed in a $90^{\circ}$ herringbone pattern. The blocks used for surface 2 had no bevel, the blocks used for surface 3 had a $2 \mathrm{~mm}$ bevel, and the blocks used for surface 4 had an $8 \mathrm{~mm}$ bevel. Sidewalk surfaces 5 and 6 were constructed of fired clay bricks in a $45^{\circ}$ herringbone pattern. The blocks used for surface 5 had a $4 \mathrm{~mm}$ bevel, and the blocks used for surface 6 had no bevel. We added three additional concrete surfaces in the third year of the study. Surfaces 7 and 8 both had a $6 \mathrm{~mm}$ bevel and were installed in $90^{\circ}$ and $45^{\circ}$ herringbone patterns, respectively. Surface 9 had a $4 \mathrm{~mm}$ bevel and was installed in a $90^{\circ}$ herringbone pattern. The specifications of the surfaces can be seen in Table 1. An Interlocking Concrete Pavement Institute (ICPI) certified contractor installed all the sidewalks.

Ten nondisabled subjects were recruited in each of the three testing years. We tried to recruit either the same subject each year or subjects with matching weights and heights to account for variability in the subject population. Subject demographics can be found in Table 2 . A repeated measures analysis of variance showed that no significant differences existed between subject height $(p=0.8)$ and weight $(p=0.4)$ over the study period.
This study was approved by the Department of Veterans Affairs (VA) Pittsburgh Healthcare System Institutional Review Board. Study requirements stated that subjects be between the ages of 18 and 65, be free of any shoulder pain that would prevent them from propelling, have no history of cardiopulmonary disease, and be free of a physical disability. After giving their written informed consent, subjects were asked to propel a manual wheelchair (at $1 \mathrm{~m} / \mathrm{s}$ ) (Figure 2) and drive a power wheelchair (at $1 \mathrm{~m} / \mathrm{s}$ and $2 \mathrm{~m} / \mathrm{s}$ ) over six sidewalk surfaces a total of three times each.

The manual wheelchair (Quickie ${ }^{\circledR}$ GP, Sunrise Medical, Carslbad, California) had a rigid-frame design, with $127 \mathrm{~mm}$-diameter polyurethane tires and standard $610 \mathrm{~mm}$ diameter rear wheels. The seat width was $406 \mathrm{~mm}$, the seat depth was $458 \mathrm{~mm}$, and the backrest height was $410 \mathrm{~mm}$. The rear axles were placed $45 \mathrm{~mm}$ in front of the backrest tubes. SmartWheels ${ }^{\circledR}$ (Three Rivers Holding, Mesa, Arizona) were used for the rear wheels during this study [20]. They were used in the first year of testing to evaluate differences in work during propulsion over all the surfaces [13] and therefore included in the following years for consistency. SmartWheels have solid-foam inserts. The approximate mass of the manual wheelchair with the SmartWheels attached was $15.5 \mathrm{~kg}$.

The power wheelchair (Quickie ${ }^{\circledR}$ P200, Sunrise Medical) had a rigid-frame design, with $203 \mathrm{~mm}$ front casters and $254 \mathrm{~mm}$-diameter rear wheels (Figure 3). The seat width was $406 \mathrm{~mm}$, the seat depth was $415 \mathrm{~mm}$, and the backrest height was $435 \mathrm{~mm}$. A standard position-sensing joystick was mounted to the right-side armrest, and the default manufacturer controller settings were used. All tires

Table 1.

Specifications of surfaces tested.

\begin{tabular}{|c|c|c|c|c|c|c|c|}
\hline \multirow{2}{*}{ Surface } & \multirow{2}{*}{ Name } & \multirow{2}{*}{ Edge Detail } & \multirow{2}{*}{ Composition } & \multicolumn{3}{|c|}{ Dimension (mm) } & \multirow{2}{*}{$\begin{array}{c}\text { Installed } \\
\text { Pattern }\end{array}$} \\
\hline & & & & Length & Width & Height & \\
\hline 1 & Poured Concrete* $^{*}$ & - & Concrete & - & - & - & Smooth \\
\hline 3 & Holland Paver & $2 \mathrm{~mm}$ bevel & Concrete & 198 & 98 & 80 & $90^{\circ}$ \\
\hline 4 & Holland Paver & 8 mm bevel & Concrete & 198 & 98 & 60 & $90^{\circ}$ \\
\hline 7 & Holland Paver & 6 mm bevel & Concrete & 198 & 98 & 60 & $90^{\circ}$ \\
\hline 8 & Holland Paver & 6 mm bevel & Concrete & 198 & 98 & 60 & $45^{\circ}$ \\
\hline 9 & Holland Paver & $4 \mathrm{~mm}$ bevel & Concrete & 198 & 98 & 60 & $90^{\circ}$ \\
\hline
\end{tabular}


Table 2.

Subject characteristics (mean \pm standard deviation) for all 3 years of study.

\begin{tabular}{ccc}
\hline Year & Height $\mathbf{( c m )}$ & Weight $\mathbf{( k g )}$ \\
\hline 1 & $170.4 \pm 11.3$ & $71.2 \pm 19.0$ \\
2 & $171.0 \pm 11.6$ & $72.0 \pm 19.4$ \\
3 & $171.0 \pm 10.8$ & $73.0 \pm 20.6$ \\
\hline \hline
\end{tabular}

were properly inflated to the rated air pressure (248.2 $\mathrm{kPa}$ for the caster and $344.7 \mathrm{kPa}$ for the rear wheels). The approximate mass of the power wheelchair with batteries was $89.0 \mathrm{~kg}$. The frame of the power wheelchair was made from aircraft-quality aluminum. All subjects sat on a $50 \mathrm{~mm}$-thick polyurethane foam cushion during all testing. Neither wheelchair was used between testing years so deterioration (specifically to the tires and frames) or other changes over time were minimized.

A triaxial accelerometer was used to collect vibration data in three orthogonal axes at the seat and the footrest. Acceleration data were collected at $200 \mathrm{~Hz}$. The ISO 26311 standard describes the minimum collection rate for accelerations as $160 \mathrm{~Hz}$. The seat accelerometer was attached to a $40.64 \times 40.64 \times 0.64 \mathrm{~cm}$ aluminum plate. The footrest accelerometer was attached to a $7.62 \times 15.24 \times 0.95 \mathrm{~cm}$ aluminum plate, which in turn was attached to the wheelchair footrest. Based on the ISO 2631-1 standard, we analyzed the WBV defined along the vertical z-axis (along the spine of a seated subject and along the legs transmitted through the footrest) using the RMS method (Equation) [18]. The choice to only measure the $z$-axis acceleration direction was based on the ISO 2631-1 standard, which states that measurements should be made in the direction of the highest vibrations. Once acceleration data were collected at the seat and the footrest for each trial, we applied frequency weightings, as described by the ISO 2631-1 standard. The frequency-weighted accelerations in the vertical direction are given as $a_{\mathrm{wz}}$ and the time of the trial is $T$. The result is the RMS acceleration in the vertical direction $\left(a_{\mathrm{rz}}\right)$ and is calculated by

$$
a_{\mathrm{rz}}=\left[\frac{1}{T} \int_{0}^{T} a_{\mathrm{wz}}^{2}(t) d t\right]^{\frac{1}{2}}
$$

The acceleration data were calibrated and converted for analyses with custom software written in MATLAB (The MathWorks Inc, Natick, Massachusetts).

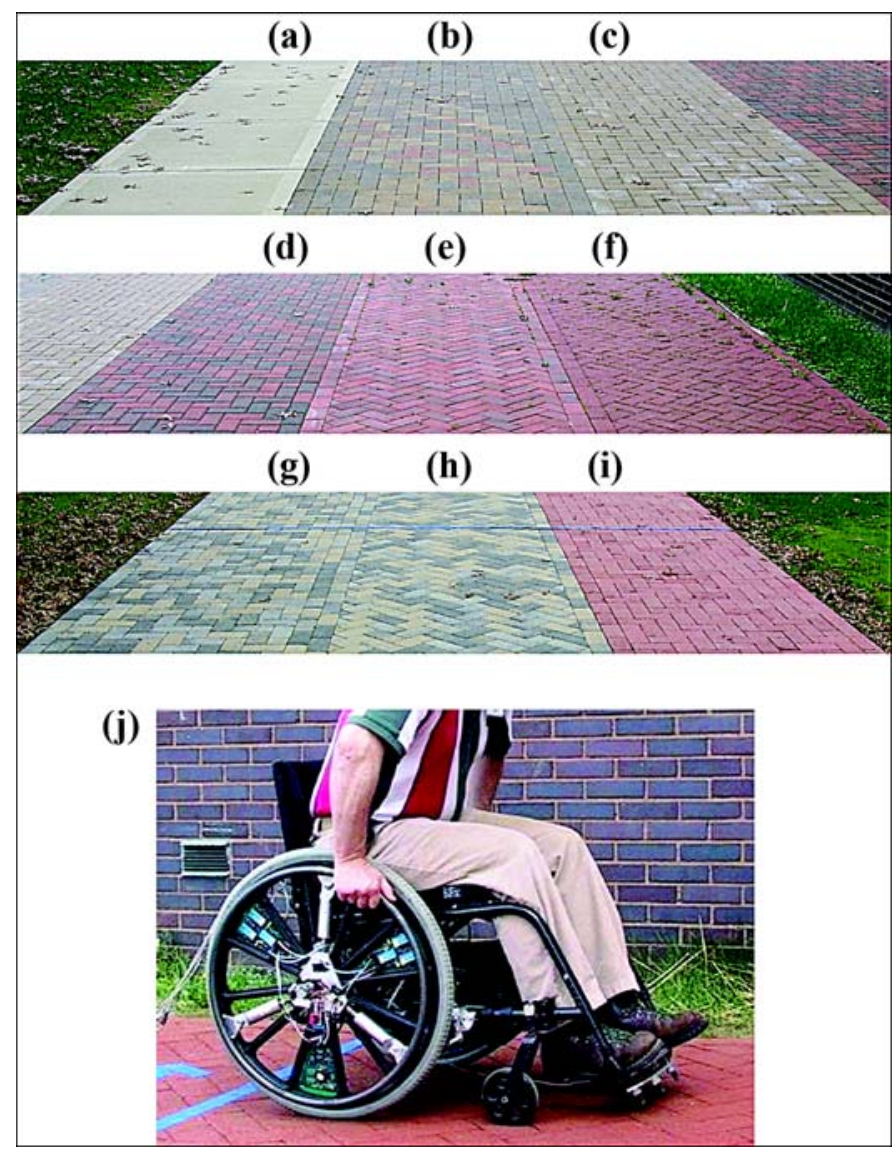

Figure 2.

Surfaces tested: (a) 1 (poured concrete), (b) 2 (concrete, no bevel), (c) 3 (concrete, $2 \mathrm{~mm}$ bevel), (d) 4 (concrete, $8 \mathrm{~mm}$ bevel), (e) 5 (brick, $4 \mathrm{~mm}$ bevel), (f) 6 (brick, no bevel), (g) 7 (concrete, $6 \mathrm{~mm}$ bevel), (h) 8 (concrete, $6 \mathrm{~mm}$ bevel), and (i) 9 (concrete, $4 \mathrm{~mm}$ bevel); (j) setup of Quickie ${ }^{\circledR}$ GP manual wheelchair (Sunrise Medical, Carlsbad, California).

Statistical analyses were performed with SAS (SAS Institute Inc, Cary, North Carolina). We analyzed the data using a mixed model to evaluate the differences in RMS vertical vibrations at the seat and footrest between surfaces and between years. Analyses between years included surfaces 1 through 6 only (poured concrete; concrete with $0 \mathrm{~mm}$, $2 \mathrm{~mm}$, and $8 \mathrm{~mm}$ bevels; and brick with $4 \mathrm{~mm}$ and $0 \mathrm{~mm}$ bevels, respectively) because surfaces 7 through 9 (concrete with $6 \mathrm{~mm}, 6 \mathrm{~mm}$ [45 pattern], and $4 \mathrm{~mm}$ bevels, respectively) were only tested in the third year. Post hoc analysis was completed with a Tukey pairwise comparison test.

\section{RESULTS}

Data were analyzed for normality. Outliers were removed and data were found to be normally distributed. 


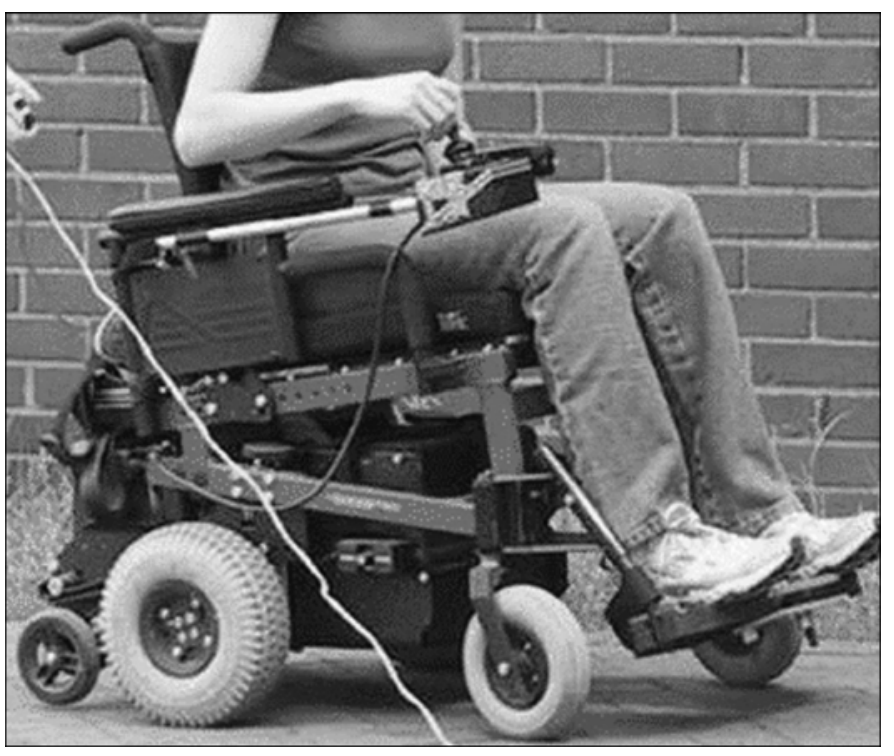

Figure 3.

Setup of Quickie ${ }^{\circledR}$ P200 power wheelchair (Sunrise Medical, Carlsbad, California).

\section{Manual Wheelchair: Surfaces}

Significant differences in vibrations at the seat and the footrest for the manual wheelchair were found between surfaces $(p<0.001)$ (Tables 3 and 4). Post hoc analysis revealed that the standard poured concrete surface (surface 1) resulted in significantly higher WBV than surfaces 2 and 3 (concrete with $0 \mathrm{~mm}$ and $2 \mathrm{~mm}$ bevel, respectively) and significantly lower WBV than surfaces 4, 7, and 8 (concrete with $8 \mathrm{~mm}, 6 \mathrm{~mm}$, and $6 \mathrm{~mm}\left[45^{\circ}\right.$ pattern] bevel, respectively). No significant differences were noted for surfaces 5 and 6 (brick with $4 \mathrm{~mm}$ and $0 \mathrm{~mm}$ [45 $5^{\circ}$ pattern] bevel, respectively).

\section{Manual Wheelchair: Years}

For RMS vibrations at the seat and the footrest, significant differences were found between the three years $(p<$ 0.001) (Tables 5 and 6). Post hoc analysis revealed that for RMS vibrations at the seat, year 1 was significantly lower than years 2 and 3 and year 2 was not significantly different than year $3(p=0.3)$. For RMS vibrations at the footrest, all three years were significantly different $(p<0.001)$.

\section{Power Wheelchair: Surfaces}

We found significant differences between surfaces in WBV for the seat and footrest at $1 \mathrm{~m} / \mathrm{s}(p<0.001)$ (Tables 3 and 4). Post hoc analysis of the data from the $1 \mathrm{~m} / \mathrm{s}$ speed revealed that at the seat, surface 2 (concrete
Table 3.

Root-mean-square vibration (mean \pm standard deviation) for wheelchair seat for manual wheelchair and power wheelchair at 2 different driving speeds for year 3 .

\begin{tabular}{|c|c|c|c|}
\hline Surface & $\begin{array}{c}\text { Manual } \\
\text { Wheelchair } \\
(1 \mathrm{~m} / \mathrm{s})\end{array}$ & $\begin{array}{c}\text { Power } \\
\text { Wheelchair } \\
(1 \mathrm{~m} / \mathrm{s})\end{array}$ & $\begin{array}{c}\text { Power } \\
\text { Wheelchair } \\
(2 \mathrm{~m} / \mathrm{s})\end{array}$ \\
\hline 1 & $0.47 \pm 0.07$ & $0.37 \pm 0.09$ & $1.17 \pm 0.21$ \\
\hline 2 & $0.32 \pm 0.06^{*}$ & $0.28 \pm 0.06^{*}$ & $0.60 \pm 0.12^{*}$ \\
\hline 3 & $0.39 \pm 0.07^{*}$ & $0.33 \pm 0.08$ & $0.67 \pm 0.12^{*}$ \\
\hline 4 & $0.76 \pm 0.16^{\dagger}$ & $0.85 \pm 0.19^{\dagger}$ & $0.89 \pm 0.14^{*}$ \\
\hline 5 & $0.46 \pm 0.09$ & $0.33 \pm 0.10$ & $0.75 \pm 0.15^{*}$ \\
\hline 6 & $0.47 \pm 0.08$ & $0.37 \pm 0.09$ & $0.90 \pm 0.14^{*}$ \\
\hline 7 & $0.59 \pm 0.09^{\dagger}$ & $0.59 \pm 0.08^{\dagger}$ & $0.76 \pm 0.10^{*}$ \\
\hline 8 & $0.78 \pm 0.09^{\dagger}$ & $0.38 \pm 0.05$ & $0.89 \pm 0.15^{*}$ \\
\hline 9 & $0.48 \pm 0.06$ & $0.40 \pm 0.05$ & $0.66 \pm 0.08^{*}$ \\
\hline
\end{tabular}

${ }^{*}$ Surfaces resulted in significantly lower whole-body vibrations (WBV) $(p<$ 0.05 ) than surface 1.

${ }^{\dagger}$ Surfaces resulted in significantly higher WBV $(p<0.05)$ than surface 1.

Table 4.

Root-mean-square vibration (mean \pm standard deviation) for wheelchair footrest for manual wheelchair and power wheelchair at 2 different driving speeds for year 3.

\begin{tabular}{|c|c|c|c|}
\hline Surface & $\begin{array}{c}\text { Manual } \\
\text { Wheelchair } \\
(1 \mathrm{~m} / \mathrm{s})\end{array}$ & $\begin{array}{c}\text { Power } \\
\text { Wheelchair } \\
(1 \mathrm{~m} / \mathrm{s})\end{array}$ & $\begin{array}{c}\text { Power } \\
\text { Wheelchair } \\
(2 \mathrm{~m} / \mathrm{s})\end{array}$ \\
\hline 1 & $1.36 \pm 0.22$ & $0.53 \pm 0.10$ & $1.26 \pm 0.31$ \\
\hline 2 & $0.81 \pm 0.18^{*}$ & $0.32 \pm 0.08^{*}$ & $0.67 \pm 0.21^{*}$ \\
\hline 3 & $1.09 \pm 0.23^{*}$ & $0.38 \pm 0.09^{*}$ & $0.79 \pm 0.19^{*}$ \\
\hline 4 & $2.30 \pm 0.44^{\dagger}$ & $0.66 \pm 0.16^{\dagger}$ & $1.21 \pm 0.28$ \\
\hline 5 & $1.34 \pm 0.32$ & $0.43 \pm 0.09$ & $0.84 \pm 0.21^{*}$ \\
\hline 6 & $1.41 \pm 0.25$ & $0.47 \pm 0.09$ & $0.94 \pm 0.23^{*}$ \\
\hline 7 & $1.79 \pm 0.29^{\dagger}$ & $0.43 \pm 0.08$ & $0.78 \pm 0.70^{*}$ \\
\hline 8 & $2.19 \pm 0.32^{\dagger}$ & $0.46 \pm 0.13$ & $0.86 \pm 0.26^{*}$ \\
\hline 9 & $1.35 \pm 0.18$ & $0.32 \pm 0.06^{*}$ & $0.67 \pm 0.16^{*}$ \\
\hline
\end{tabular}

${ }^{*}$ Surfaces resulted in significantly lower whole-body vibrations (WBV) $(p<$ $0.05)$ than surface 1.

${ }^{\dagger}$ Surfaces resulted in significantly higher WBV $(p<0.05)$ than surface 1.

with $0 \mathrm{~mm}$ bevel) resulted in significantly lower WBV than surface 1 . Surfaces $3,5,6,8$, and 9 (concrete with $2 \mathrm{~mm}$ bevel, brick with $4 \mathrm{~mm}$ bevel, brick with $0 \mathrm{~mm}$ bevel [ $45^{\circ}$ pattern], concrete with $6 \mathrm{~mm}$ bevel, and concrete with $4 \mathrm{~mm}$ bevel, respectively) were not significantly different than the standard poured concrete surface. Surface 4 (concrete with $8 \mathrm{~mm}$ bevel) and surface 7 (concrete with $6 \mathrm{~mm}$ bevel) resulted in significantly higher WBV 
Table 5.

Root-mean-square vibration (mean \pm standard deviation) for wheelchair seat over 3 years for manual wheelchair and power wheelchair at 2 different driving speeds.

\begin{tabular}{cccc}
\hline Year & $\begin{array}{c}\text { Manual } \\
\text { Wheelchair } \\
(\mathbf{1} \text { m/s) }\end{array}$ & $\begin{array}{c}\text { Power } \\
\text { Wheelchair } \\
(\mathbf{1} \text { m/s) }\end{array}$ & $\begin{array}{c}\text { Power } \\
\text { Wheelchair } \\
\mathbf{( 2 ~} \mathbf{~ m} / \mathbf{s})\end{array}$ \\
\hline 1 & $0.44 \pm 0.17$ & $0.40 \pm 0.19$ & $0.78 \pm 0.21$ \\
2 & $0.49 \pm 0.15^{*}$ & $0.45 \pm 0.23$ & $0.83 \pm 0.23$ \\
3 & $0.50 \pm 0.18^{*}$ & $0.42 \pm 0.20$ & $0.89 \pm 0.22$ \\
\hline "Not significantly different. & & \\
\hline
\end{tabular}

Table 6 .

Root-mean-square vibration (mean \pm standard deviation) for wheelchair footrest over 3 years for manual wheelchair and power wheelchair at 2 different driving speeds.

\begin{tabular}{|c|c|c|c|}
\hline Year & $\begin{array}{c}\text { Manual } \\
(1 \mathrm{~m} / \mathrm{s})\end{array}$ & $\begin{array}{l}\text { Power } \\
(1 \mathrm{~m} / \mathrm{s})\end{array}$ & $\begin{array}{l}\text { Power } \\
(2 \mathrm{~m} / \mathrm{s})\end{array}$ \\
\hline 1 & $1.27 \pm 0.53$ & $0.48 \pm 0.17^{*}$ & $0.94 \pm 0.32$ \\
\hline 2 & $1.39 \pm 0.50$ & $0.45 \pm 0.14$ & $0.90 \pm 0.29$ \\
\hline 3 & $1.49 \pm 0.57$ & $0.47 \pm 0.14^{*}$ & $1.02 \pm 0.33$ \\
\hline
\end{tabular}

than surface 1 (poured concrete). At the footrest, surfaces 2,3 , and 9 resulted in significantly lower WBV than surface 1; surfaces 5 to 8 were not significantly different, and surface 4 resulted in significantly higher WBV.

We found significant differences between surfaces in WBV for the seat and footrest at $2 \mathrm{~m} / \mathrm{s}(p<0.001)$. Post hoc analysis of the data from the $2 \mathrm{~m} / \mathrm{s}$ speed revealed that at the seat, all surfaces resulted in significantly lower WBV than the standard poured concrete surface. At the footrest, all surfaces resulted in significantly lower WBV than the standard poured concrete surface except surface 4, which did not result in significantly different WBV.

\section{Power Wheelchair: Years}

For RMS vibrations at the seat and the footrest, we found significant differences in years at $1 \mathrm{~m} / \mathrm{s}$ and at $2 \mathrm{~m} / \mathrm{s}$ $(p<0.001)$ (Tables 5 and 6). For RMS vibrations at the footrest, post hoc analysis revealed that year 1 was not significantly different from year $3(p=0.2)$ at $1 \mathrm{~m} / \mathrm{s}$.

\section{DISCUSSION AND CONCLUSIONS}

Based on its nature, a wheelchair represents a system in which its user will be subjected to WBV in a seated position for long durations. Because the ISO 2631-1 standard requires an 8-hour rest period to negate the damaging effects of any transmitted vibrations [18] and because power wheelchair users typically rely on their wheelchair for all of their mobility, wheelchair users are potentially at high risk of secondary injuries from WBV.

Wheelchair users experience pain over the course of the day for multiple reasons. Sitting for long periods of time and exposure to WBV can cause discomfort. Maeda et al. issued a questionnaire to wheelchair users to determine if WBV experienced during wheelchair propulsion caused discomfort [14]. Results showed that the WBV experienced during propulsion did cause discomfort, specifically at the neck, lower back, and buttocks. Maeda et al.'s study and other studies that measured WBV levels during wheelchair use [12,15-17] show that WBV exposure may cause discomfort and eventually pain in wheelchair users.

The results of this study showed that surfaces other than poured concrete should be considered for pedestrian access routes. ICP and brick surfaces that have small bevels may decrease the amount of WBV that are transmitted to wheelchair users during propulsion, especially at higher speeds.

The results showing differences in the surfaces were expected based on previous studies and the physical properties of the surfaces [13]. Surface 4 had the largest bevel $(8 \mathrm{~mm})$ and resulted in the most vibration. Surface 2 had the smallest bevel $(0 \mathrm{~mm})$ and resulted in the lowest vibration.

\section{Manual Wheelchairs}

Results for the manual wheelchair showed that surfaces 2 and 3 (concrete with $0 \mathrm{~mm}$ and $2 \mathrm{~mm}$ bevel, respectively) produced significantly lower RMS vibrations than the poured concrete surface. These surfaces present a good alternative to the standard poured concrete because they transmit less WBV to wheelchair users. This result contradicts the statement from the Public Rights-of-Way Access Advisory Committee, who claim that surfaces composed of individual units are undesirable because of the vibrations they cause (http://www.access-board.gov/ prowac/commrept/index.htm). We found differences in RMS vibration between surfaces over years for the manual wheelchair at both the seat and the footrest, with RMS vibrations increasing over time.

\section{Power Wheelchairs}

Results for the power wheelchair were also promising for the use of alternative surfaces that reduce 
the amount of WBV transmitted to wheelchair users. At $1 \mathrm{~m} / \mathrm{s}$, surface 2 resulted in significantly lower WBV at the seat than the standard poured concrete surface and surfaces 2, 3, and 9 resulted in significantly lower WBV at the footrest. At $2 \mathrm{~m} / \mathrm{s}$, all surfaces resulted in significantly lower WBV than the standard concrete surface at the seat; at the footrest, only surface 4 was not significantly different, while all other surfaces resulted in significantly lower WBV. The results from the data collected at $2 \mathrm{~m} / \mathrm{s}$ are most likely caused by breaks in the poured concrete surface. The higher speed of the wheelchair causes greater transmission of shocks from breaks in the sidewalk. We also found significant differences in years at the seat and the footrest for both speeds for the power wheelchair. No trend was noted for increase or decrease of RMS vibrations over years. The results from the change in the surfaces over years suggests that data have not been collected long enough to show either an increase or decrease in WBV. Data should continue to be collected to more appropriately analyze the trend of change over time.

We hypothesized that wear on the bevels from weather or normal use would reduce the amount of vibrations experienced by the wheelchair user. The results, however, showed an increase in RMS vibration at the seat and the footrest for the manual wheelchair and the power wheelchair at $2 \mathrm{~m} / \mathrm{s}$. This increase may have occurred for several reasons. The nine tested surfaces were isolated and did not see normal wear from travel and use, which could result in similar results over multiple years. Heaving and settling of the ICP and brick pavers may occur over time and could cause sharper transitions, resulting in higher RMS vibrations. Finally, significant differences over time may not exist, even if results are followed for longer periods. Limitations of this study include no use of a standard surface, such as smooth tile, for comparing surfaces with a baseline control. However, the standard poured concrete was used as the control surface because it is the most common outdoor pedestrian surface. No additional pedestrian wear on any of the surfaces was noted. In a real-world situation, such wear would exist on surfaces from normal use. However, keeping the surfaces in a controlled environment allowed the comparison to be more accurate, because the wear on all surfaces was equal. Only one manual and one power wheelchair were used for this study. Certain wheelchairs are capable of reducing the amount of WBV transmitted to wheelchair users, how- ever, because differences in surfaces were being examined, rigid-frame manual and power wheelchairs were selected for this study.

The recruitment of nondisabled subjects and different subjects over the years is a further limitation of this study and could have resulted in differences in propulsion style during manual wheelchair driving. Although, the sitting biomechanics of wheelchair users and nondisabled subjects may be different, we chose this subject population based on ease of recruitment over multiple years and because the metric of interest was the difference between a standard poured concrete surface and ICP or brick surfaces. Additionally, we assumed that matching the height and weight of the replacement subjects controlled for important factors of WBV measurement.

These results demonstrate that some ICP surfaces should be considered for wheelchair access routes and may reduce the amount of WBV transmitted to wheelchair users, specifically the surfaces with the smallest bevels. The results clearly show that many of the ICP surfaces are as good if not better than the standard poured concrete surface at reducing the amount of WBV transmitted to wheelchair users. Additionally, some surfaces may produce levels of WBV exposure that could cause secondary injuries to both manual and power wheelchair users over time.

\section{ACKNOWLEDGMENTS}

This material was based on work partially supported by a consortium of the ICPI, the Brick Industry Association, and the National Concrete Masonry Association. In addition, funding was provided by the VA Rehabilitation Research and Development Service (grant F2181C), the U.S. Department of Education, National Institute on Disability and Rehabilitation Research, Rehabilitation Engineering Research Center on Wheeled Mobility (H133E990001), and a National Science Foundation Graduate Research Fellowship.

The ICPI, the Brick Industry Association, and the National Concrete Masonry Association were not involved in any of the study design; data collection, analysis, or interpretation; and writing or submission of this article. 


\section{REFERENCES}

1. Cooper RA, Thorman T, Cooper R, Dvorznak MJ, Fitzgerald SG, Ammer W, Song-Feng G, Boninger ML. Driving characteristics of electric-powered wheelchair users: How far, fast, and often do people drive? Arch Phys Med Rehabil. 2002;83(2):250-55. [PMID: 11833031]

2. Griffin MJ. Handbook of human vibrations. San Diego (CA): Academic Press; 1990. p. 173-86.

3. Thompson C, Bélanger M. Effects of vibration in inline skating on the Hoffman reflex, force, and proprioception. Med Sci Sports Exerc. 2002;34(12):2037-44. [PMID: 12471313]

4. Frendo F, Sgueglia M, Vitale E, Hippoliti R. Analysis of motorscooter ride comfort. In: Proceedings of the Conference of Automotive and Transportation Technology; 2002; Paris (France).

5. Pope MH, Wilder DG, Magnusson ML. A review of studies on seated whole body vibration and low back pain. Proc Inst Mech Eng [H]. 1999;213(6):435-46. [PMID: 10635692]

6. Mansfield NJ, Griffin MJ. Effect of magnitude of vertical whole-body vibration on absorbed power for the seated human body. J Sound Vibration. 1998;215(4):813-26.

7. Bovenzi M, Hulshof CT. An updated review of epidemiologic studies on the relationship between exposure to whole-body vibration and low back pain. Int Arch Occup Environ Health. 1999;72(6):351-65. [PMID: 10473835$]$

8. Griffin MJ. Vertical vibration of seated subjects: Effects of posture, vibration level, and frequency. Aviat Space Environ Med. 1975;46(3):269-76. [PMID: 1115729]

9. Wan Y, Schimmels JM. Optimal seat suspension design based on minimum "simulated subjective response." J Biomed Eng. 1997;119(4):409-16. [PMID: 9407279]

10. Nishiyama K, Taoda K, Kitahara T. A decade of improvement in whole-body vibration and low back pain for freight-container tractor drivers. J Sound Vibration. 1998; 215(4):635-42.

11. Wilder D, Magnusson ML, Fenwick J, Pope M. The effect of posture and seat suspension design on discomfort and back muscle fatigue during simulated truck driving. Appl Ergon. 1994;25(2):66-76. [PMID: 15676952]

12. VanSickle DP, Cooper RA, Boninger ML, DiGiovine CP. Analysis of vibrations induced during wheelchair propulsion. J Rehabil Res Dev. 2001;38(4):409-21. [PMID: 11563494]
13. Wolf E, Pearlman J, Cooper RA, Fitzgerald SG, Kelleher A, Collins DM, Boninger ML, Cooper R. Vibration exposure of individuals using wheelchairs over sidewalk surfaces. Disabil Rehabil. 2005;27(23):1443-49. [PMID: $16418059]$

14. Maeda S, Futatsuka M, Yonesaki J, Ikeda M. Relationship between questionnaire survey results of vibration complaints of wheelchair users and vibration transmissibility of manual wheelchair. Environ Health Prev Med. 2003;8(3): 82-89.

15. Cooper RA, Wolf E, Fitzgerald SG, Boninger ML, Ulerich $\mathrm{R}$, Ammer WA. Seat and footrest shocks and vibrations in manual wheelchairs with and without suspension. Arch Phys Med Rehabil. 2003;84(1):96-102. [PMID: 12589628]

16. Kwarciak AM, Cooper RA, Wolf E. Effectiveness of rear suspension in reducing shock exposure to manual wheelchair users during curb descents. In: Proceedings of the 25th Annual Rehabilitation Engineering and Assistive Technology Society of North America (RESNA) Conference [CD-ROM]; 2002 Jun 27-Jul 1; Minneapolis, MN. Washington (DC): RESNA; 2002.

17. Wolf E, Cooper RA, Kwarciak AM. Analysis of wholebody vibrations of suspension manual wheelchairs: Utilization of the absorbed power method. In: Proceedings of the 25th Annual Rehabilitation Engineering and Assistive Technology Society of North America (RESNA) Conference [CD-ROM]; 2002 Jun 27-Jul 1; Minneapolis, MN. Washington (DC): RESNA; 2002.

18. International Standards Organization (ISO). ISO 2631-1: Mechanical vibration and shock-Evaluation of human exposure to whole-body vibration-Part 1: General requirements. Geneva (Switzerland): International Standards Organization; 1997.

19. Japan Interlocking Block Association. The problem and measures of interlocking block pavement for eyesight or walking disabled people. Washington, DC: Interlocking Concrete Pavement Institute. 1993; p. 6-24.

20. Asato KT, Cooper RA, Robertson RN, Ster JF. SMARTWheels: Development and testing of a system for measuring manual wheelchair propulsion dynamics. IEEE Trans Biomed Eng. 1993;40(12):1320-24. [PMID: 8125507]

Submitted for publication May 24, 2006. Accepted in revised form February 26, 2007. 